Table 1. Cost of Consumables Used for Central Sterile Supply Department (CSSD) Environmental Quality Monitoring Purposes

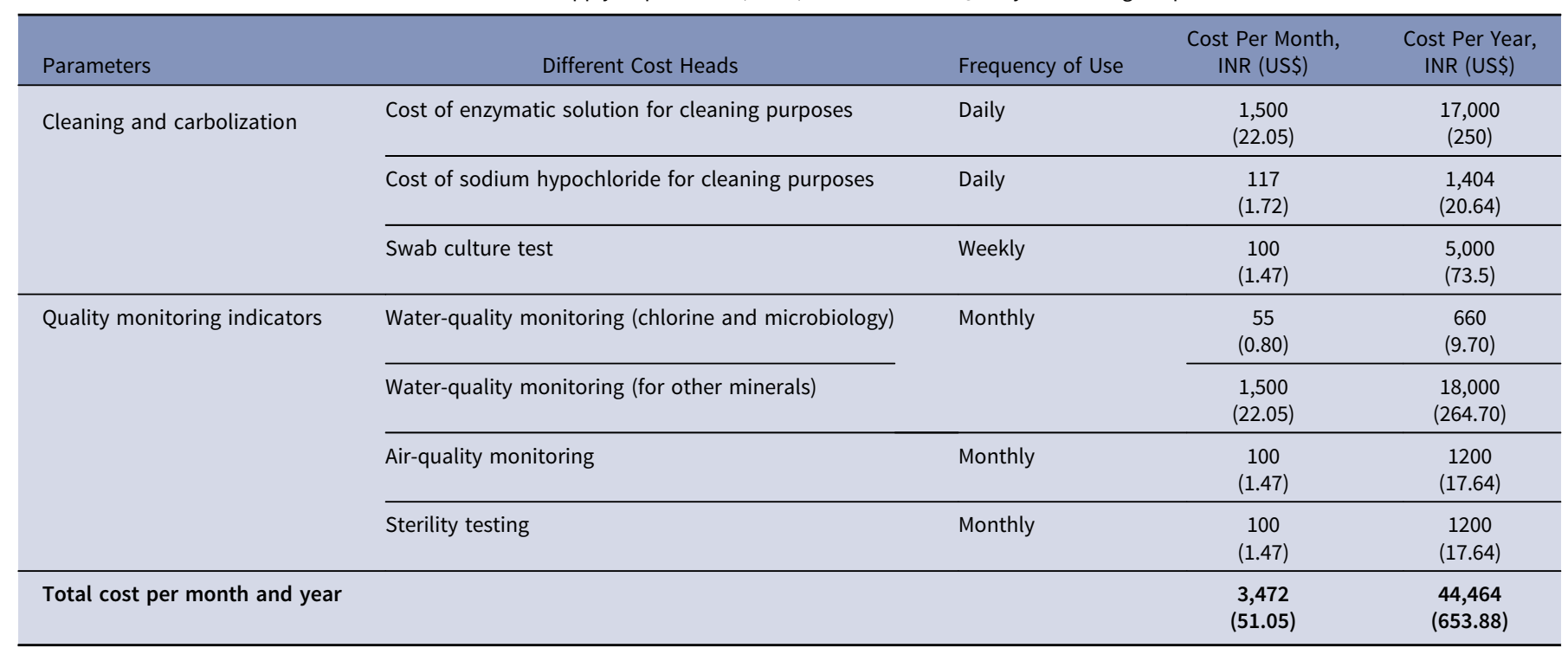

Note. INR, Indian rupees.

Acknowledgment. None.

Financial support. No financial support was provided relevant to this article.

Conflicts of interest. All authors report no conflicts of interest relevant to this article.

Supplementary material. To view supplementary material for this article, please visit https://doi.org/10.1017/ice.2020.41

\section{References}

1. Central service technical manual. International Association of Healthcare Central Service Materiel Management website. https://www.iahcsmm.org/ publications/central-service-technical-training-8/crcst-8th-ed-manual-contents. html. Accessed August 22, 2019.

2. Guideline for disinfection and sterilization in healthcare facilities. Centers for Disease Control and Prevention website. http://www.cdc.gov/hicpac/ disinfection sterilization/1700recommendations.html. Published 2008, Accessed February 6, 2020.
3. Bhalchandra R, Chandy M, Ramanan VR, et al. Role of water quality assessments in hospital infection control: experience from a new oncology center in eastern India. Indian J Pathol Microbiol 2014;57:435-438.

4. Clean rooms and associated controlled environments, part 2: specifications for testing and monitoring to prove continued compliance with ISO 14644-1. International Standards Organization website. https://www.iso.org/obp/ui/ \#iso:std:iso:14644:-2:ed-1:en. Accessed August 22, 2019.

5. KEYA KALP national guidelines for clean hospitals. Ministry of Health and Family Welfare Government of India website. https://mohfw.gov.in/ sites/default/files/7660257301436254417_0.pdf. Accessed August 22, 2019.

6. Sterilization of medical devices, microbiological methods, part 2: tests of sterility performed in the definition, validation and maintenance of a sterilization process. International Standards Organization website. https://www.iso.org/ obp/ui/\#iso:std:iso:11737:-2:en. Accessed August 22, 2019.

7. European expert condemns the re-use of sterilization packaging. Irish Decontamination Institute website. http://www.deconidi.ie/html/educ/ articles/educarticle_0001.htm. Accessed August 22, 2019.

8. Basu D, Bhattacharya S, Mahajan A, Ramanan VR, Chandy M. The importance of the central sterile supply department in infection prevention and control. Infect Control Hosp Epidemiol 2014;35:1312-1314.

\title{
Reprocessing of single-use medical devices and their associated problems: an experience from a cancer center in eastern India
}

\author{
Debabrata Basu $\mathrm{MSC}^{1}$ (1), Mousumi Dhara $\mathrm{MA}^{2}$ and Sanjay Kishore Dutta BCom ${ }^{1}$ \\ ${ }^{1}$ Central Sterile Supply Department, Tata Medical Center, Kolkata, India and ${ }^{2}$ Materials Department, Tata Medical Center, Kolkata, India
}

Author for correspondence: Debabrata Basu, E-mail: debabrata.basu@tmckolkata.com Cite this article: Basu D, Dhara M, and Dutta SK. (2020). Reprocessing of single-use medical devices and their associated problems: an experience from a cancer center in eastern India. Infection Control \& Hospital Epidemiology, 41: 625-627, https://doi.org/ $10.1017 /$ ice.2020.54
To the Editor-Transmission of infectious agents can occur through unclean and unsterile medical devices. Breakdown of sterility of medical devices may lead to the transmission of bacterial and viral pathogens, including those associated with multidrug resistance. Costly medical devices must be reprocessed, and the decontamination process must be conducted under stringent quality 
control. The central sterile supply department (CSSD) plays an important role in ensuring that these medical devices are sterilized and delivered to various users in the hospital in a quality-assured environment. Here, we discuss the reprocessing of so-called single-use medical devices (SUDs) in a hospital CSSD as well as some advantages and limitations of cleaning, disinfection, and sterilization. ${ }^{1}$

\section{Complex instrument design}

Many instruments are available in the medical supply market that cannot be cleaned and sterilized properly due to their complex design; nevertheless, they are declared reusable. Basically, surgical instruments are divided into 2 categories: heat-resistant (metallic) and heat sensitive (nonmetallic, eg, rubber or plastic) where difficulty of reprocessing based on their geometric design (ie, outside shape, lumen, surface, valves and seals), the material used (ie, chemical property, passive layer, corrosion properties and thermal stability), and their construction (eg, ease of disassembly or dead-end areas). ${ }^{2}$ However, the reprocessing of nonmetallic instruments is more critical than that of metallic instruments because these instruments mainly have specialized uses. The complexities of nonmetallic instruments include their design composition (ie, splits, screws, lumen, and flushing channels), their potential for contamination due to frequent use, and their lack of thermal stability due to plastic or rubber components. ${ }^{3}$ Also, these devices are often manufactured with the expectation that they will be discarded after a single use.

\section{Reprocessing difficulties}

Body fluids polymerize on instrument surfaces when they are allowed to dry. Thus, instruments must remain wet in area where they are used and must be transferred immediately thereafter to the CSSD. After handover in CSSD, the surgical instruments are disassembled before cleaning. The CSSD should have enough space, with proper cleaning facilities: a manual or mechanical wash system, water jets, suitable cleaning brushes, and a good ventilation system. The instruments should be immersed completely in a neutral enzymatic where proper contact time and concentration should be measured to achieve safe and effective cleaning; electrically powered surgical instruments should not be immersed but should be wiped thoroughly. ${ }^{4}$ To protect instruments from disinfecting agents that fix soils (ie, aldehydes or per-acetic acid), cleaning should be done prior to disinfection so that fixation of soil can be avoided. Thorough washing then takes place using a manual or mechanical method that requires purified and pressurized water. Sterilization is conducted according to the instrument's thermal stability and the manufacturer's recommendations if available. Finally, monitoring and documentation should be proper for legal purposes and for future requirement.,

\section{Single-use device reuse policy}

In every hospital, a committee makes decisions about reprocessing SUDs. Committee members from administration, infection control, central services, surgical services, materials and finance departments should have enough knowledge of reprocessing SUDs to evaluate the related legal, ethical, and economic issues. ${ }^{2}$
The main reason for reprocessing SUDs is to reduce the charges to the patient, and patient consent may not be required if there is a stringent standard policy for reusing SUDs. ${ }^{7}$ If full charges were made for every new SUD, people from poor or developing countries would not be able to afford medical services. ${ }^{8,9}$ Additional aspects related to reusing SUDs include device availability, patient safety, equipment availability, and reprocessing time or technique. Any decision to reprocess an SUD product should include a thorough review of the manufacturer's user's manual, including any written policies for cleaning, disinfection, and sterilization. ${ }^{3}$ Finally, the committee must determine the maximum number of uses for each device as well as the charge to the patient: maximum retail price of the device (MRP) divided by the number of uses.

In our 400-bed cancer center in eastern India, the number reuses is based on our hospital reuse policy and the cost of the product. If the SUD cost is $\leq 10,000$ INR (US\$142.85), the charges to the patient will be one-third of the total MRP. Similarly, if an item costs 10,000 INR, the charges will be one-fifth of the total MRP, and if an item costs 30,000 INR ( US\$428.57), the charges will be one-tenth of the total MRP. Thus, the patient need not pay more than 2, 000 INR (US\$28.57) to 3,000 INR (US\$42.85) for a single item. Below 2,000 INR, SUDs are not reused, according to our policy. Software containing date, product name, unique code, frequency of use, and patient's identification number is used to maintain all the records of reused SUDs and to calculate the number uses along with cost.

In conclusion, the CSSD represents a neglected area of the infection control system in a hospital. Investment in well-equipped CSSD infrastructure is necessary for the smooth functioning of a hospital. Resources should be directed not only toward the development of physical infrastructure and the equipment in the CSSD but also toward the recruitment and retention of technically qualified personnel who are able to operate the system effectively. Every CSSD technician must know the importance of infection control and thoroughly understand their role in the process. Ensuring effective functioning of the CSSD is essential for infection prevention in any hospital. ${ }^{9}$

\section{Acknowledgments. None.}

Financial support. No financial support was provided relevant to this article.

Conflicts of interest. All authors report no conflicts of interest relevant to this article.

\section{References}

1. Allison VD. Hospital central sterile supply departments. Br Med J 1960;2: 772-778.

2. Sebben JE. Sterilization and care of surgical instruments and supplies. J Am Acad Dermatol 1984;3:381-392.

3. Mayer RR, Bederman SS, Colin VM, Berger MM, Cesario TC, Schwarzkopf R. Risk of contamination in assembled versus disassembled instruments in hip arthroplasty surgery. J Arthroplasty 2016;31:1746-1749.

4. Basu D. The importance of chemical solutions used for cleaning stainless steel surgical instruments in the central sterile supply department. Infect Control Hosp Epidemiol 2015;36:868-869.

5. Guideline for disinfection and sterilization in healthcare facilities. Centers for Disease Control and Prevention website. http://www.cdc.gov/hicpac/ disinfection sterilization/17 00recommendations.html. Published 2008. Accessed February 11, 2020. 
6. Basu D. Requirement of hollow process challenge device for monitoring hollow and complex instruments sterilization: a simulator for proper sterility assurance. Infection Control Hosp Epidemiol 2019;40:951-952.

7. Collier R. The ethics of reusing single-use devices. CMAJ 2011;183:1245.

8. Lee RC, Berzins S, Alfieri N. Single-use device reuse risks. Can J Infect Control 2007;22:142-146.
9. Fast O, Fast C, Fast D, Veltjens S, Salami Z, White MC. Limited sterile processing capabilities for safe surgery in low-income and middle-income countries: experience in the Republic of Congo, Madagascar, and Benin. BMJ Glob Health 2017;2 suppl 4:e000428.

\title{
An influenza A outbreak in Iranian individuals following Arba'een foot pilgrimage from October to December 2019
}

\author{
Rasoul Mirzaei $\mathrm{PhD}^{1}$ and Milad $\mathrm{Abdi}^{2,3}$ \\ ${ }^{1}$ Department of Microbiology, School of Medicine, Hamadan University of Medical Sciences, Hamadan, Iran, ${ }^{2}$ Student Research Committee, Faculty of Medicine, \\ Iran University of Medical Sciences, Tehran, Iran and ${ }^{3}$ Department of Microbiology, School of Medicine, Iran University of Medical Sciences, Tehran, Iran
}

To the Editor-Influenza A (flu) is a viral infection that involves the human respiratory system mostly in cold seasons. ${ }^{1-3}$ For most individuals, this infection is not problematic, but it can cause death. ${ }^{1}$ The transmission of this disease is done in 2 direct and indirect ways. ${ }^{4}$ Direct transmission occurs person-to-person: respiratory droplets are transmitted from infected to healthy individuals over a short distance. ${ }^{4}$ The influenza virus can survive for hours in cold conditions and in low humidity in the environment. Hand contact with contaminated surfaces or objects can transmit the virus indirectly thorough inoculation of the eyes, nose, and mouth. ${ }^{4}$ Individuals at high risk for developing deadly flu are members of the following groups ${ }^{5}$ : (1) adults $>65$ years of age, (2) children $<5$ years of age, (3) pregnant women, (4) individuals with weakened immune defenses, (5) individuals with chronic disorders (eg, heart disease, asthma, kidney disease, diabetes as well as liver disorder), and (6) obese individuals. Up to 650,000 deaths annually are associated with respiratory diseases from seasonal influenza, according to new estimates by the Centers for Disease Control and Prevention (CDC), the World Health Organization, and their global health partners. ${ }^{6}$ In 2019, in Western Asia, influenza activity remained elevated overall and continued to increase in Iraq, Israel, Jordan, Turkey, and Yemen. ${ }^{7}$

During the 20th and 21st centuries, 5 influenza pandemics have been recorded: Spanish (1918-1920), Asian (1957-1958), Hong Kong (1968-1969), Russian (1977-1978), and H1N1/09 pandemic flu (2009-2010). ${ }^{8}$ During the last pandemic of influenza (JuneNovember 2009), 2,662 cases of pandemic influenza A (H1N1) were detected in Iran. Among these cases, 58 patients died. ${ }^{8}$ The most common influenza A outbreaks in Iran had been $\mathrm{H} 1 \mathrm{~N} 1$, the most severe form of the disease, which accounted for $\sim 90 \%$ of all cases. ${ }^{9}$ Seasonal influenza is among the most prevalent infectious diseases in travelers. ${ }^{10}$ In tropical areas, influenza viruses may circulate throughout the year with several seasonal peaks, whereas in the moderate climate zones, circulation is largely limited to 1 or 2 peaks in the fall and winter months. ${ }^{10}$ Studies have shown the relationship between overcrowding and increased prevalence of influenza. ${ }^{11}$ Thus, whenever and wherever high population density

Author for correspondence: Rasoul Mirzaei, E-mail: rasul.micro92@gmail.com Cite this article: Mirzaei R and Abdi M. (2020). An influenza A outbreak in Iranian individuals following Arba'een foot pilgrimage from October to December 2019. Infection Control \& Hospital Epidemiology, 41: 627-628, https://doi.org/10.1017/ ice. 2020.49 occurs, the likelihood of transmission and spread of influenza is higher. Globally, one of the most overcrowded events is Arba'een, and it is accompanied by a high incidence of the flu every year.

Arba'een, the 40th day, is a religious event observed in many Islamic countries; it is one of the largest pilgrimage gatherings on Earth. ${ }^{12}$ In this event, up to 17 million people from Islamic countries such as Iran, Pakistan, Turkey, Afghanistan, Azerbaijan, Lebanon, Kuwait, Bahrain, Saudi Arabia travel to Karbala city in Iraq. ${ }^{12} \mathrm{~A}$ significant percentage of this population is Iranian. ${ }^{12}$ In 2018, 123,000 Iranian pilgrims had symptoms of illness upon returning to the border, and $\sim 5,000$ needed treatment due to flu. ${ }^{13}$ In 2019, 30,000 cases of influenza were reported overall, and 106 of these patients died. According to reports from Ministry of Health and Medical Education of Iran, between the beginning of October 2019 and December 2019, after pilgrims returned from Iraq, 8,333 people went to medical centers because of respiratory illness, half of whom required $>2$ days of hospitalization due to the severity of respiratory illness and 106 of whom died. ${ }^{14}$ The rest were discharged with outpatient or temporary hospitalization. ${ }^{14}$ Many factors are involved in influenza prevalence in the Arba'een. ${ }^{3}$ (1) Many pilgrims suffer from general weakness and fatigue due to a lengthy walk; some walk $\sim 200$ $\mathrm{km}$. (2) Overcrowding occurs in huge tents called mukeb, which cover thousands of people, and congestion in and around the shrine is high, increasing the risk of flu 10 -fold. ${ }^{11}$ (3) Hygiene is poor due to inadequate availability of showers and toilets. (4) The Arba'een event takes place during the cold-weather season in a geographic location with moderate climate. (5) Access to appropriate food during travel is limited. When a person has the flu, it is crucial to eat small amounts of the right foods to provide it with energy and nutrients for recovery). (6) Inadequate sleep can affect the immune system. Pilgrims who do not get quality sleep or enough sleep are more likely to get sick after being exposed to the flu virus. (7) Individuals from different countries can carry mutant and virulent influenza virus. Because of these problems and conditions in the Arba'een pilgrimage, recommend several ways for pilgrims to prevent flu outbreaks in these places ${ }^{15}$ :

1) Wash hands several times a day with liquid soap and water as well as alcohol rub if it is available.

2) Avoid contact with contaminated hands, eyes, and mouth. 